\title{
Minimally invasive versus open transforaminal lumbar fusion: a systematic review of complications
}

\author{
Wei Hu${ }^{1} \cdot$ Jiandong Tang ${ }^{1} \cdot$ Xianpei Wu ${ }^{1} \cdot$ Li Zhang $^{1} \cdot$ Baoyi Ke $^{1}$
}

Received: 17 February 2016 / Accepted: 6 March 2016 / Published online: 18 March 2016

(C) The Author(s) 2016. This article is published with open access at Springerlink.com

\begin{abstract}
Purpose The aim of this study is to compare mTLIF vs. oTLIF with regard to peri-operative complications, operative time, estimated blood loss, fluoroscopic time, and the length of hospital stay.

Methods The PubMed and EMBASE databases were searched for relevant articles reporting patients undergoing TLIF, and a comparison between MTILF and OTLIF was performed. The database included patient demographic information, complications, operative time, fluoroscopic time, and the length of hospital stay.

Results Fourteen studies were included in this systematic review. The total number of subjects included was 901 , of which 455 underwent mTLIF $(50 \%)$ and 446 underwent oTLIF (50\%). The operating time for the mTLIF was ranged from 116 to 390 minutes, compared with 102 to 365 minutes for oTLIF, the operating time tended to be longer in the mTLIF group than the oTLIF group. The estimated blood loss was lower in the mTLIF group, ranging from 51 to $578 \mathrm{ml}$ in mTLIF and 225 to $961 \mathrm{ml}$ in oTLIF, respectively. Length of
\end{abstract}

Wei $\mathrm{Hu}$

howie189@126.com

Jiandong Tang

38679060@qq.com

Xianpei $\mathrm{Wu}$

wuxianpei189@126.com

Baoyi Ke

kebaoyi@tom.com

1 Department Spine and Osteopathy Ward, Guilin Peoples' Hospital, No 12 Wenming road, Guilin, Guangxi, China 540021 hospital stay was short for the mTLIF with a 2.3 to 10.6 days hospitalization compared to 2.9 to 14.6 days for oTLIF. However the fluoroscopic time was consistently higher in the mTLIF group with a 49 to 106 seconds of fluoroscopy compared to 16.4 to 44 seconds for oTLIF. The complications divided into technical complications and infection complications. The main technical and infection complications included dural tears, screw malposition, and wound infection. Systemic complications included pneumonia, urinary tract infection, and DVT. The numbers of patients with complication was 54 out of $455(11.87 \%)$ in the mTLIF, and 64 out of 446 $(14.35 \%)$ in the oTLIF.

Conclusion The review shows mTLIF offers several potential advantages in reducing blood loss and the length of hospital stay, especially lowering the complication rates for patients compared with oTLIF. However, it required much more operative time and radiation exposure. Class I evidence and highquality randomized controlled trials are needed for further study.

Keywords Complications · Minimally invasive spine surgery · Transforaminal lumbar interbody fusion

Transforaminal lumbar interboby fusion (TLIF) has been widely performed for degenerative lumbar disease since Harms [1] popularized the procedure. It provides circumferential spinal fusion, restores disc height, and maintains the normal lordosis of the lumbar spine. Due to these advantages and good fusion rates in $95 \%$ [2-6], TLIF has been proven as a safe and effective technique in the past three decades. However, extensive paravertebral muscle stripping and retraction during the procedure to obtain an adequate surgical field causes significant soft tissue injury. This iatrogenic 
injury may lead to an increase in back pain and atrophy of the paraspinous muscles. With the development of modern image guidance and advanced instrumentation, the TLIF procedure was recently adapted to a minimally invasive procedure. The first minimally invasive technique for TLIF (mTLIF) was reported by Foley [7] in 2003. This procedure has been prevalent in recent years as it is associated with smaller wounds, fewer soft tissue injuries, reduced blood loss, and faster recovery compared to the traditional open TLIF procedure (oTLIF) [8]. Although numerous studies on the differences between mTLIF and oTLIF have been performed, at present, there is no consensus between spinal surgeons as to the benefits of mTLIF over oTLIF.

This study aimed to evaluate the literature to compare mTLIF vs. oTLIF with regard to peri-operative complications, operative time and the length of hospital stay. The specific questions that our study aimed to answer are: (1) Is there a significant difference in the incidence of technical complications such as dural tears and screw malposition with mTLIF compared with oTLIF? (2) Does mTLIF significantly reduce infectious complications like wound infection and systemic complications in comparison to oTLIF? (3) Is the operative time taken for mTLIF significantly greater than with oTLIF? (4) Is mTLIF associated with a reduced length of postoperative stay?

\section{Materials and methods}

\section{Search strategy}

Two authors (H.W and ZH.L) searched the PubMed and EMBASE databases for relevant articles published up to August 2015. The studies reporting patients undergoing TLIF, with emphasis on a comparison between minimally invasive and traditional open access, were searched. Search terms included "minimally invasive pedicle screw", "percutaneous pedicle", "minimally invasive percutaneous pedicle screw", "minimally invasive spine surgery", "spinal microsurgery", and "transforaminal lumbar interbody fusion" (TLIF). A search of the references of the obtained manuscripts was also performed.

\section{Inclusion criteria}

We searched all the studies reporting patients undergoing TLIF surgery, with an emphasis on the comparison between mTLIF and oTLIF with the outcome and complications. Reports must have contained at least one outcome of: the operative time, length of hospital stay, fluroscopic time, and complications.

\section{Exclusion criteria}

The following criteria were used to exclude studies from our analysis:

1. Case reports, technical notes, reviews, and animal or cadaver studies were discarded. All the studies published in a language other than English were also discarded.

2. Studies on indications other than degenerative lumbar disease, spinal stenosis or grade I-II lumbar spondylolithesis were discarded, such as fracture, metastatic tumor, and idiopathic scoliosis.

3. Studies describing either open or MIS (minimally invasive surgery) posterior lumbar interbody fusion (PLIF) were discarded.

4. Studies about revision surgery concluded on patients who needed multi-level decompression and fusion were discarded.

5. Studies in which the outcomes of interest were not reported for the two techniques or where it was impossible to calculate these from the published results.

\section{Review procedure and data extraction}

After being selected, studies were screened independently by two authors (H.W and ZH.L); in cases where there was a discrepancy, the decision was taken by consensus. The following data were extracted: (1) first author, (2) year of publication, (3) numbers of patients undergoing mTLIF or oTLIF, (4) patient characteristics, (5) study design (e.g., prospective, retrospective, randomized controlled or others), (6) quality of the study, (7) numbers of complications, (8) complication types, and (9) complication rate. Any disagreements were solved by discussion if necessary.

\section{Quality assessment}

The Newcastle-Ottawa Scale (NOS)[9] was used to assess the quality of these non-randomized studies. This measure assesses aspects of methodology in observational studies related to study quality, including Selection (4 points), Comparability ( 2 points), and Exposure ( 3 points). The ordinal star scoring scale ranged from 0-9 stars (points). Studies with higher scores represented studies of higher quality.

\section{Results}

\section{Study identification and selection}

A total of 88 initial articles were searched in the database. Nineteen of these were excluded because they were 
duplications, studies on animals and cadavers, or in languages other than English. After screening the titles and abstracts of the remaining 69 articles, 25 of these were excluded. The excluded studies included two technical notes, six reviews, three commentaries, and 14 studies not pertinent to mTLIF. The full text of the remaining 44 articles was reviewed for more detail. The indications investigated in 12 articles were fracture, metastatic tumor or idiopathic scoliosis; as they were on indications other than lumbar degenerative diseases, these studies were excluded. The articles that included revision surgery (8) or more than a single level treated (6) or without the complications were also excluded. Eventually, 14 studies which met our inclusion criteria were included in the present systematic review [10-23]. The selection process for articles included in the review is shown in Fig. 1.

\section{Study characteristics}

All of the 14 remaining studies comparing mTLIF vs. oTLIF were cohort studies including seven prospective and seven retrospective cohorts. None of them was a randomized controlled trial or case-control study. The main characteristics of the 14 cohort studies included in this systematic review are presented in Table 1. The quality assessment and scores according to the NOS, which was used to assess the quality of these non-randomized studies, are shown in Table 2.

The studies publication dated from 2007 to 2015 and the sample size of the studies ranged from 10 to 72 . The total number of subjects included was 901, of which 455 underwent mTLIF (50\%) and 446 underwent oTLIF $(50 \%)$. The total mean age of patients was 53 years. Of the patients, $55.75 \%$ were female. One study did not provide a gender distribution. Mean clinical follow-up ranged from a minimum of six months to a maximum of 60 months. All the patients reported spinal stenosis, grade I-II lumbar spondylolisthesis, lumbar herniated nucleus pulposus, or another degenerative lumbar disease. The specific complication rate and type of each study is given in Table 3. One study did not provide details on complications.

\section{Surgical outcomes}

The operating time for the mTLIF was ranged from 116 to 390 minutes, compared with 102 to 365 minutes for oTLIF, the operating time tended to be longer in the mTLIF group than the oTLIF group ( $n=11$ studies) [10-12, 16-23]. The estimated blood loss was generally and significantly lower in the mTLIF group, ranging from 51 to $578 \mathrm{ml}$ in mTLIF and 225 to $961 \mathrm{ml}$ in oTLIF, respectively ( $n=13$ studies) [10-13, 15-23]. Length of hospital stay was short for the mTLIF with a 2.3 to 10.6 days hospitalization compared to 2.9 to 14.6 days for oTLIF( $\mathrm{n}=12$ studies)[11-15, 17-23]. However the fluoroscopic time was consistently higher in the mTLIF group with a 49 to $106 \mathrm{~s}$ of fluoroscopy compared to 16.4 to $44 \mathrm{~s}$ for oTLIF ( $n=6$ studies) $[12,15,18,20-22]$. The clinic outcomes are shown in Table 4.
Fig. 1 Selection process of articles in the systematic review

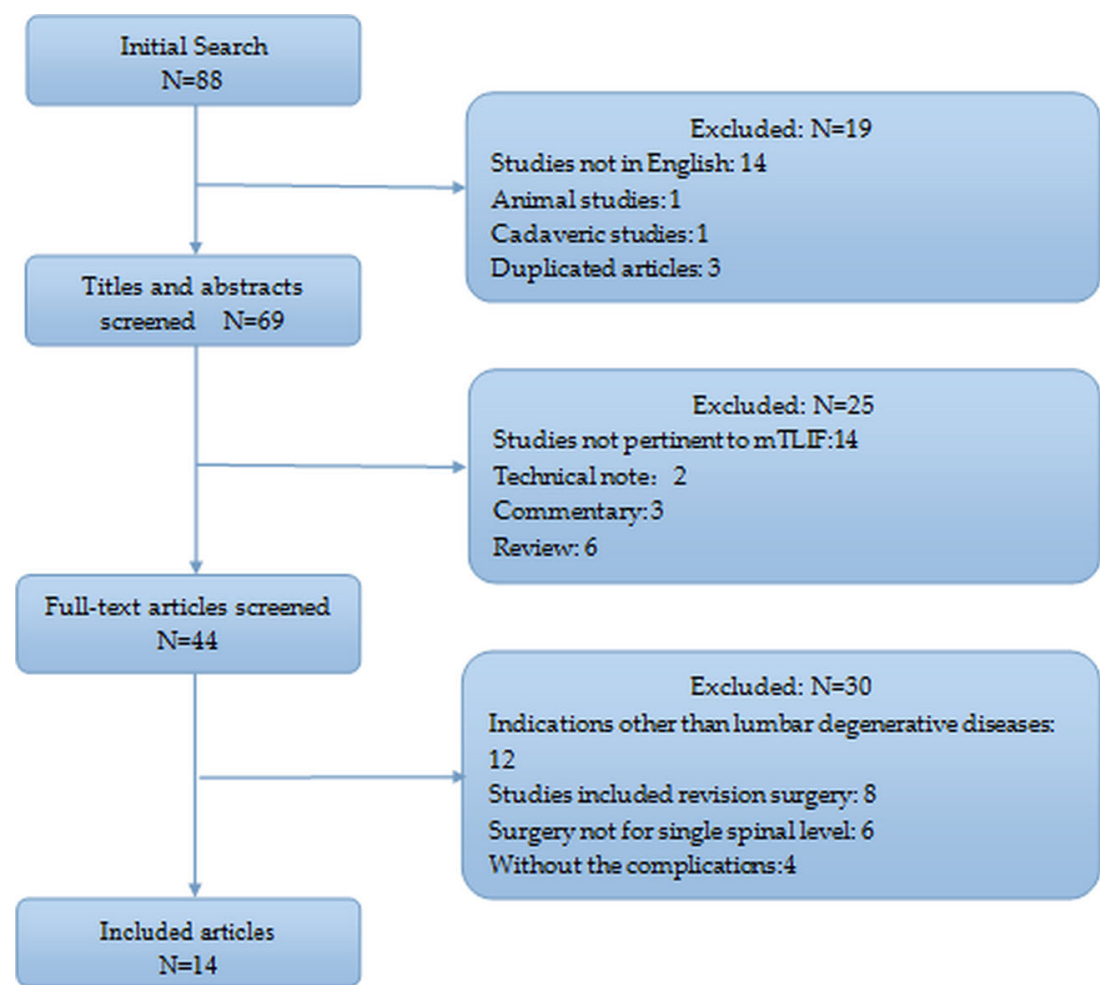


Table 1 Demographics of included studies

\begin{tabular}{|c|c|c|c|c|c|c|c|c|}
\hline \multirow[t]{2}{*}{ Study year } & \multicolumn{2}{|l|}{ NO. } & \multicolumn{2}{|c|}{ Mean age } & \multirow[t]{2}{*}{$\mathrm{P}$} & \multicolumn{2}{|c|}{$\%$ Female } & \multirow[t]{2}{*}{$\mathrm{P}$} \\
\hline & mTLIF & oTLIF & mTLIF & oTLIF & & mTLIF & oTLIF & \\
\hline Archavlis 2013 [10] & 24 & 23 & 67.0 & 68.0 & 0.94 & 58.0 & 68.0 & 0.917 \\
\hline Brodano 2013 [11] & 30 & 34 & 46.0 & 51.0 & ND & 40.0 & 41.2 & ND \\
\hline Seng 2013 [12] & 40 & 40 & 56.6 & 56.8 & $>0.05$ & 47.1 & 47.1 & $>0.05$ \\
\hline Singh 2013 [13] & 33 & 33 & 51.7 & 49.9 & 0.56 & 30.3 & 36.4 & 0.602 \\
\hline Mobbs 2012 [14] & 37 & 30 & 68.6 & 67.4 & 0.74 & 48.6 & 46.7 & 0.87 \\
\hline Lee 2012 [15] & 72 & 72 & 52.2 & 56.6 & 0.06 & 72.2 & 69.4 & 0.714 \\
\hline Adogwa 2011 [16] & 15 & 15 & 50.8 & 49.7 & 0.77 & 53.3 & 66.7 & 0.71 \\
\hline Lau 2011 [17] & 10 & 12 & 46.9 & 56.9 & 0.02 & 60.0 & 58.0 & 0.64 \\
\hline Wang HL 2011 [18] & 41 & 38 & 51.4 & 57.3 & 0.44 & 41.5 & 39.5 & ND \\
\hline Fan 2010 [19] & 32 & 30 & 51.4 & 52.0 & 0.06 & 43.8 & 53.3 & 0.45 \\
\hline Wang J 2010 [20] & 42 & 43 & 47.9 & 53.2 & $\mathrm{ND}$ & 69.0 & 62.8 & ND \\
\hline Peng 2009 [21] & 29 & 29 & 54.1 & 52.5 & ND & 82.8 & 82.8 & ND \\
\hline Schizas 2009 [22] & 18 & 18 & 45.5 & 48.1 & $\mathrm{ND}$ & ND & ND & ND \\
\hline Park 2007 [23] & 32 & 29 & 62.1 & 59.0 & & 75.0 & 55.2 & 0.10 \\
\hline Total & 455 & 446 & & & & & & \\
\hline
\end{tabular}

$\mathrm{ND}=$ not documented

\section{Complicantions}

The complications were divided into technical complications and infection complications. The main technical and infection complications included dural tears, screw malposition, and wound infection. Systemic complications included pneumonia, urinary tract infection, and DVT. The rate and types of complication in the included studies was shown in Table 3. The numbers of patients with complication was 54 out of $455(11.87 \%)$ in the mTLIF, and 64 out of $446(14.35 \%)$ in the oTLIF.
Table 2 Assessment of study quality

\begin{tabular}{|c|c|c|c|c|c|c|c|c|c|c|c|}
\hline \multirow[t]{3}{*}{ Study year } & \multirow[t]{3}{*}{ Study design } & \multicolumn{10}{|c|}{ Quality indicators from the Newcastle-Ottawa scale } \\
\hline & & \multicolumn{4}{|c|}{ Selection } & \multicolumn{2}{|c|}{ Comparable } & \multicolumn{3}{|c|}{ Outcome assessment } & \multirow[t]{2}{*}{ Score } \\
\hline & & 1 & 2 & 3 & 4 & 5 & 6 & 7 & 8 & 9 & \\
\hline Archavlis 2013 [10] & $\mathrm{R}$ & * & * & * & * & $*$ & * & * & * & * & 9 \\
\hline Brodano 2013 [11] & $\mathrm{R}$ & * & $*$ & * & * & & & $*$ & * & * & 7 \\
\hline Seng 2013 [12] & $\mathrm{R}$ & * & $*$ & $*$ & $*$ & $*$ & * & $*$ & * & $*$ & 9 \\
\hline Singh 2013 [13] & $\mathrm{P}$ & * & $*$ & $*$ & $*$ & $*$ & $*$ & $*$ & * & * & 9 \\
\hline Mobbs 2012 [14] & $\mathrm{P}$ & * & $*$ & * & * & $*$ & & $*$ & * & $*$ & 8 \\
\hline Lee 2012 [15] & $\mathrm{P}$ & * & $*$ & * & * & $*$ & & * & * & $*$ & 8 \\
\hline Adogwa 2011 [16] & $\mathrm{R}$ & * & $*$ & $*$ & * & $*$ & & $*$ & * & * & 8 \\
\hline Lau 2011 [17] & $\mathrm{R}$ & * & $*$ & * & * & & & $*$ & * & $*$ & 7 \\
\hline Wang HL 2011 [18] & $\mathrm{R}$ & * & * & * & * & $*$ & & $*$ & * & * & 8 \\
\hline Fan 2010 [19] & $\mathrm{P}$ & * & * & * & * & $*$ & & * & * & * & 8 \\
\hline Wang J 2010 [20] & $\mathrm{P}$ & * & * & * & * & & & * & * & * & 7 \\
\hline Peng 2009 [21] & $\mathrm{P}$ & * & $*$ & * & * & & & * & * & * & 7 \\
\hline Schizas 2009 [22] & $\mathrm{R}$ & * & & * & * & & & $*$ & * & * & 6 \\
\hline Park 2007 [23] & $\mathrm{P}$ & * & * & * & * & $*$ & & $*$ & * & $*$ & 8 \\
\hline
\end{tabular}


Table 3 The rate and types of complication in the included studies

\begin{tabular}{|c|c|c|c|c|}
\hline \multirow[t]{2}{*}{ Study year } & \multicolumn{2}{|c|}{ Rate of complications $\mathrm{N}(\%)$} & \multicolumn{2}{|l|}{ Types of complication } \\
\hline & mTLIF & oTLIF & mTLIF & oTLIF \\
\hline Archavlis 2013 [10] & $8(33.33)$ & $9(36.00)$ & $\begin{array}{l}\text { Radiculopathy contralateral } 2 \\
\text { Revision surgery } 2 \\
\text { Revision pedicle screw } 1 \\
\text { Suspected pseudarthrosis } 1 \\
\text { Adjacent segment disease } 1 \\
\text { Incidental durotomy } 1\end{array}$ & $\begin{array}{l}\text { Incidental durotomy } 1 \\
\text { Revision surgery } 2 \\
\text { Suspected pseudarthrosis } 1 \\
\text { Wound healing disturbance } 3 \\
\text { Adjacent segment disease } 2\end{array}$ \\
\hline Brodano 2013 [11] & $1(3.33)$ & $3(8.82)$ & Dural lesion 1 & Dural lesion 2 screw malposition 1 \\
\hline Seng 2013 [12] & $6(15.00)$ & $8(20.00)$ & $\begin{array}{l}\text { Durotomy } 1 \\
\text { Adjacent segment disease } 4\end{array}$ & $\begin{array}{l}\text { Iliac crest infection } 1 \\
\text { Durotomy } 1 \text { iliac crest infection } 1 \\
\text { Adjacent segment disease } 4 \text { Pneumonia } 1 \\
\text { Undisplaced fracture of right L4 pedicle } 1\end{array}$ \\
\hline Mobbs 2012 [14] & $2(5.4)$ & $10(33.3)$ & $\begin{array}{l}\text { Infection } 1 \\
\text { Haematoma } 1\end{array}$ & $\begin{array}{l}\text { Infection } 2 \\
\text { Postoperative radiculopathy } 1 \\
\text { Paralytic ileus } 3 \\
\text { Deep vein thrombosis } 1 \\
\text { Dural tear } 1 \\
\text { Non union } 2\end{array}$ \\
\hline Lee 2012 [15] & $7(9.72)$ & $9(12.5)$ & $\begin{array}{l}\text { Durotomy } 1 \\
\text { Pneumonia1 } \\
\text { Screw malposition } 1 \\
\text { Cage migration } 4\end{array}$ & $\begin{array}{l}\text { Wound abscess } 1 \\
\text { Pneumonia1 } \\
\text { Myocardial infarction } 1 \\
\text { Cage migration } 6\end{array}$ \\
\hline Adogwa 2011 [16] & 0 & $1(6.67)$ & None & Hematoma 1 \\
\hline Lau $2011[17]$ & $4(10)$ & $1(8.3)$ & $\begin{array}{l}\text { Wound infection } 1 \\
\text { Rod not captured by screw } 1 \\
\text { Ventricular tachycardia } 1 \\
\text { Pseudarthrosis } 1\end{array}$ & Pseudarthrosis 1 \\
\hline Wang HL 2011 [18] & $3(7.32)$ & $4(10.53)$ & $\begin{array}{l}\text { Nerve root injury } 1 \\
\text { Pneumonia } 1 \\
\text { Superficial wound infection } 1\end{array}$ & $\begin{array}{l}\text { Superficial wound infection } 2 \\
\text { Pneumonia } 1 \text { wound fat liquefaction } 1\end{array}$ \\
\hline Fan 2010 [19] & $6(18.75)$ & $5(16.67)$ & $\begin{array}{l}\text { Screw malposition } 2 \\
\text { Ileus } 1\end{array}$ & Superficial Wound infection 1 \\
\hline & & & Superficial wound infection 3 & Ileus 2 \\
\hline & & & & $\begin{array}{l}\text { Deep wound infection } 1 \\
\text { Deep venous thrombosis } 1\end{array}$ \\
\hline Wang J 2010 [20] & $5(11.90)$ & $4(9.30)$ & $\begin{array}{l}\text { Graft dislodgement } 1 \\
\text { Dural tear } 2 \\
\text { Epidural hematoma } 1 \\
\text { Nonunion } 1\end{array}$ & $\begin{array}{l}\text { Dural tear } 2 \\
\text { Nonunion } 1 \\
\text { Screw malposition } 1\end{array}$ \\
\hline Peng 2009 [21] & $2(6.9)$ & $4(13.8)$ & Iliac crest infection 2 & $\begin{array}{l}\text { Atelectasis } 1 \\
\text { Urinary tract infection } 2 \\
\text { Wound infection } 1\end{array}$ \\
\hline Schizas 2009 [22] & $6(33.33)$ & $2(11.11)$ & $\begin{array}{l}\text { Dural tear } 1 \\
\text { Brachial plexus palsy } 1\end{array}$ & L3 radicular pain 1 \\
\hline & & & $\begin{array}{l}\text { L5 root paresis } 1 \\
\text { Nonunion } 3\end{array}$ & Cage ruptured 1 \\
\hline Park 2007 [23] & $4(12.5)$ & $4(13.8)$ & $\begin{array}{l}\text { Screw malposition } 1 \\
\text { Cage migration } 1 \\
\text { Deep wound infection } 1 \\
\text { Nonunion } 1\end{array}$ & $\begin{array}{l}\text { Superficial wound infection } 2 \\
\text { Nonunion } 1 \\
\text { Deep wound infection } 1\end{array}$ \\
\hline Singh 2013 [13] & ND & ND & ND & ND \\
\hline Total & 54 & 64 & & \\
\hline
\end{tabular}

$\mathrm{ND}=$ not documented

\section{Discussion}

Although mTLIF has been reported as a safe and efficient surgical treatment with reduced blood loss, earlier ambulation, and shorter hospitalization, the question of complication rates between MTLIF and oTLIF has remained unanswered. There were differences in complication morbidity, such as technical or infectious complication, in different treatment groups among published studies. In order to minimize the heterogeneity, only single-level surgery was included, and revision 
Table 4 Clinic outcomes

\begin{tabular}{|c|c|c|c|c|c|c|c|c|}
\hline \multirow[t]{2}{*}{ Study year } & \multicolumn{2}{|c|}{$\begin{array}{l}\text { Operating time } \\
\text { (min) }\end{array}$} & \multicolumn{2}{|c|}{$\begin{array}{l}\text { Estimated blood } \\
\text { loss (ml) }\end{array}$} & \multicolumn{2}{|c|}{$\begin{array}{l}\text { Length of } \\
\text { hospital stay }\end{array}$} & \multicolumn{2}{|c|}{$\begin{array}{l}\text { Fluroscopic time } \\
\text { (second) }\end{array}$} \\
\hline & mTLIF & oTLIF & mTLIF & oTLIF & mTLIF & oTLIF & mTLIF & oTLIF \\
\hline Archavlis 2013 [10] & 220 & 190 & 185 & 225 & ND & ND & ND & $\mathrm{ND}$ \\
\hline Brodano 2013 [11] & 144 & 102 & 230 & 620 & 4.1 & 7.4 & ND & ND \\
\hline Seng 2013 [12] & 185 & 166 & 127 & 405 & 3.6 & 5.9 & 55.2 & 16.4 \\
\hline Singh 2013 [13] & 116 & 186 & 124 & 380 & 2.3 & 2.9 & ND & $\mathrm{ND}$ \\
\hline Mobbs 2012 [14] & ND & $\mathrm{ND}$ & ND & ND & 5.9 & 9.7 & ND & $\mathrm{ND}$ \\
\hline Lee 2012 [15] & 166 & 182 & 51 & 447 & 3.2 & 6.8 & 49 & 17 \\
\hline Adogwa 2011 [16] & 300 & 210 & 200 & 295 & ND & ND & ND & $\mathrm{ND}$ \\
\hline Lau 2011 [17] & 390 & 365 & 466 & 566 & 5 & 8.3 & ND & ND \\
\hline Wang HL 2011 [18] & 169 & 145 & 208 & 259 & 6.4 & 8.7 & 93 & 44 \\
\hline Fan 2010 [19] & 159 & 143 & 578 & 711 & 9.3 & 12.5 & ND & ND \\
\hline Wang J 2010 [20] & 156 & 145 & 264 & 673 & 10.6 & 14.6 & 84 & 37 \\
\hline Peng 2009 [21] & 216 & 170 & 150 & 681 & 4.0 & 6.7 & 106 & 35 \\
\hline Schizas 2009 [22] & 348 & 312 & 456 & 961 & 6.1 & 8.2 & $2.7^{*}$ & 1.8 \\
\hline Park 2007 [23] & 192 & 149 & 433 & 738 & 5.3 & 10.8 & ND & $\mathrm{ND}$ \\
\hline Total & 455 & 446 & & & & & & \\
\hline
\end{tabular}

${ }^{*}$ intraoperative radiation exposure as expressed in dose area product $\left(\mathrm{cGy} / \mathrm{cm}^{2}\right)$

surgery was excluded. In this systematic review, we searched for articles with the complications divided into technical complications and infection complications. The main technical and infection complications included dural tears, screw malposition, and wound infection. Systemic complications included pneumonia, urinary tract infection, DVT of the latter.

The total incidence of complications were $11.87 \%$ (45/ $455)$ and $14.35 \%(64 / 446)$ in the mTLIF and oTLIF, respectively. The common technical complications were dural tears (7 cases) $[10-12,14,19,21]$ and screw malposition ( 6 cases) $[10,14,16,18,23]$. In the minimally invasive system (MIS) procedure, because of the small working portal, the standard anatomic landmarks are not visible, so the surgery is more technically demanding and difficult than oTLIF. Placement of the pedicle screw is more skill-dependent in MTLIF than in oTLIF. The computer tomograph assessment provides axial and coronal images that also make the percutaneous pedicle screw insertion more accurate. It is possible that when the surgeon performing MIS masters the skill, technical complications will be reduced.

The propotion of patients with wound infection was $12 \%$ $(7 / 54)$ in the mTLIF group and $25 \%(16 / 64)$ in the oTLIF group. This may demonstrate that the reduced soft tissue injuries in the MTLIF have a positive effect on the wound healing process. There were two cases of systemic complication in the mTLIF group, including one case of ileus [18], and the other of pneumonia [16]. However, there were six cases of that in the oTLIF which consist of three pneumonia [12, 14, 17], one DVT, one ileus, and one atelectasis. This was possibly due to the longer duration of immobility in the oTILF group compared to the mTILF group. Furthermore, the shorter duration of hospital stay may also reduce the risk of nosocomial infection. This may be a type II error because of the small sample size and may reach statistical significance with a larger sample size.

Almost all the studies [10-12], [16-23] reporting mTLIF required a longer operative time than oTLIF. The concept of a minimally invasive procedure taking longer than its open equivalent is not surprising. The difference may be caused by the mTLIF technical learning curve as a new technique, while oTLIF has been mastered fluently. The articles included initial learning cases, while oTLIF is familiar to surgeons. Brodano [11] divided the MTLIF group of patients into chronologically distinct equal subgroups (15 early cases vs. 15 later cases); there was a statistically significant difference in operative time ( 3.2 hours for the 15 early cases, 1.8 hours for the 15 later cases). So, if the surgeon masters the skills and gains adequate experience in MTLIF, the operative time becomes almost equal to that in the oTLIF group. Furthermore, considering the instrumentation used during MTLIF surgery and the setup time involved, as well as more radiological imaging assistance in the placement of screw and cages required, the total operative time increased.

There was a consensus that MTLIF provides a statistically significant shorter length of hospital stay in the studies included in this systematic review. It shows that mTLIF significantly reduced the length of hospital stay compared with oTLIF. These results may be related to the less invasive nature of the procedure and fewer resulting soft tissue injuries, as well as reduced blood loss and wound pain. This in turn translated 
to earlier ambulation to recovery and shorter hospitalization than in the oTLIF group.

Because of the smaller operative field and lack of visualization of the bony landmarks, the fluoroscopy exposure in the mTLIF was higher than that in the oTLIF [24]. Radiation exposure was a potential health hazard to the operating surgeon during mTLIF with continued exposure during surgery. Minimally invasive lumbar surgery cases expose the surgeon to significantly more radiation than open lumbar surgery [25].

\section{Study limitations}

The limitations of this systematic review are as follows. First, there were no randomized controlled trials studies included in this review, namely without class I evidence, even though we used criteria to reduce heterogeneity. Second, the sample size we collected may not have been large enough to influence the results such that potential significant differences were not found.

\section{Conclusion}

The review shows mTLIF offers several potential advantages in reducing blood loss and the length of hospital stay, especially lowering the complication rates for patients compared with oTLIF. However, it required much more operative time and radiation exposure. Class I evidence and high-quality randomized controlled trials are needed for further study.

\section{Compliance with ethical standards}

Disclosure The authors declare no conflict of interest.

Open Access This article is distributed under the terms of the Creative Commons Attribution 4.0 International License (http:// creativecommons.org/licenses/by/4.0/), which permits unrestricted use, distribution, and reproduction in any medium, provided you give appropriate credit to the original author(s) and the source, provide a link to the Creative Commons license, and indicate if changes were made.

\section{References}

1. Harms J, Rolinger H (1982) A one-stage procedure in operative treatment of spondylolithesis: dorsal traction-reposition and anterior fusion (author's transl). Z Orthop Ihre Grenzgeb 120:343-347

2. Humphreys SC, Hodges SD, Humphreys SC, Hodges SD, Patwardhan AG, Eck JC, Murphy RB, Covington LA (2001) Comparison of posterior and transforaminal approaches to lumbar interbody fusion. Spine (Phila Pa 1976) 26:567-571

3. Lowe TG, Tahernia AD, O'Brien MF, Smith DA (2002) Unilateral transforaminal posterior lumbar interbody fusion (TLIF): indications, technique, and 2-year results. J Spinal Disord Tech 15(1): $31-38$
4. Rosenberg WS, Mummaneni PV (2001) Transforaminal lumbar interbody fusion: technique, complications and early results. Neurosurgery 48(3):569-574, discussion 574-5

5. Salehi SA, Tawk R, Ganju A, LaMarca F, Liu JC, Ondra SL (2004) Transforaminal lumbar interbody fusion: surgical technique and results in 24 patients. Neurosurgery 54(2):368-374, discussion 374

6. Potter BK, Freedman BA, Verwiebe EG, Hall JM, Polly DW Jr, Kuklo TR (2005) Transforaminal lumbar interbody fusion: clinical and radiographic results and complications in 100 consecutive patients. J Spinal Disord Tech 18(4):37-46

7. Foley KT, Gupta SK (2002) Percutaneous pedicle screw fixation of the lumbar spine: preliminary clinical results. J Neurosurg 97(1 suppl):7-12

8. Lucio JC, Vanconia RB, Deluzio KJ, Lehmen JA, Rodgers JA, Rodgers W (2012) Economics of less invasive spinal surgery: an analysis of hospital cost differences between open and minimally invasive instrumented spinal fusion procedures during the perioperative period. Risk Manag Healthc Policy 5:65-74. doi:10.2147/ RMHP.S30974

9. Wells GA, Shea B, O'Connell D, Peterson J, Welch V, Losos M, Tugwell P (2004) The Newcastle-Ottawa Scale (NOS) for assessing the quality of nonrandomised studies in meta-analyses. http://www. ohri.ca/programs/clinical_epidemiology/oxford.htm. Accessed April 29, 2004

10. Archavlis E, Carvi YNM (2013) Comparison of minimally invasive fusion and instrumentation versus open surgery for severe stenotic spondylolisthesis with high-grade facet joint osteoarthritis. Eur Spine J 22:1731-1740. doi:10.1007/s00586-013-2732-6

11. Brodano GB, Martikos K, Lolli F, Gasbarrini A, Cioni A, Bandiera S, Silvestre MD, Boriani S, Greggi T (2015) Transforaminal lumbar interbody fusion in degenerative disk disease and spondylolisthesis grade I: minimally invasive versus open surgery. J Spinal Disord Tech 28(10):E559-E564. doi:10.1097/BSD.0000000000000034

12. Seng C, Siddiqui MA, Wong KP, Zhang K, Yeo W, Tan SB, Yue WM (2013) Five-year outcomes of minimally invasive versus open transforaminal lumbar interbody fusion: a matched-pair comparison study. Spine (Phila Pa 1976) 38(23):2049-2055. doi:10.1097/BRS. 0b013e3182a8212d

13. Singh K, Nandyala SV, Marquez-Lara A, Fineberg SJ, Oglesby M, Pelton MA, Andersson GB, Isayeva D, Jegier BJ, Phillips FM (2014) A peri-operative cost analysis comparing single-level minimally invasive and open transforaminal lumbar interbody fusion. Spine J 14(8):1694-1701. doi:10.1016/j.spinee.2013.10.053 16

14. Mobbs RJ, Sivabalan P, Li J (2012) Minimally invasive surgery compared to open spinal fusion for the treatment of degenerative lumbar spine pathologies. J Clin Neurosci 19(6):829-835. doi:10. 1016/j.jocn.2011.10.004

15. Lee KH, Yue WM, Yeo W, Soeharno H, Tan SB (2012) Clinical and radiological outcomes of open versus minimally invasive transforaminal lumbar interbody fusion. Eur Spine J 21(11):22652270. doi:10.1007/s00586-012-2281-4

16. Adogwa O, Parker SL, Bydon A, Cheng J, McGirt MJ (2011) Comparative effectiveness of minimally invasive versus open transforaminal lumbar interbody fusion: 2-year assessment of narcotic use, return to work, disability, and quality of life. J Spinal Disord Tech 24(8):479-484. doi: 10.1097/BSD.0b013e3182055cac

17. Lau D, Lee JG, Han SJ, Lu DC, Chou D (2011) Complications and perioperative factors associated with learning the technique of minimally invasive transforaminal lumbar interbody fusion (TLIF). J Clin Neurosci 18(5):624-7. doi:10.1016/j.jocn.2010.09.004

18. Wang HL, Lü FZ, Jiang JY, Ma X, Xia XL, Wang LX (2011) Minimally invasive lumbar interbody fusion via MAST quadrant retractor versus open surgery: a prospective randomized clinical trial. Chin Med J 124(23):3868-3874 
19. Fan SW, Zhao X, Zhao FD et al (2010) Minimally invasive transforminal lumbar interbody fusion for the treatment of degenerative lumbar disease. Spine 35(17):1615-20

20. Wang J, Zhou Y, Zhang ZF, Li CQ, Zheng WJ, Liu J (2010) Comparison of one-level minimally invasive and open transforaminal lumbar interbody fusion in degenerative and isthmic spondylolisthesis grades 1 and 2. Eur Spine J 19(10):1780-1784. doi:10.1007/s00586-010-1404-Z

21. Peng CW, Yue WM, Poh SY, Yeo W, Tan SB (2009) Clinical and radiological outcomes of minimally invasive versus open transforaminal lumbar interbody fusion. Spine (Phila Pa 1976) 34(13):1385-1389. doi:10.1097/BRS.0b013e3181a4e3be

22. Schizas C, Tzinieris N, Tsiridis E, Kosmopoulos V (2009) Minimally invasive versus open transforaminal lumbar interbody fusion: evaluating initial experience. Int Orthop 33(6):1683-1688. doi:10.1007/s00264-008-0687-8

23. Park Y, Ha JW (2007) Comparison of one-level posterior lumbar interbody fusion performed with a minimally invasive approach or a traditional open approach. Spine 32(5):537-543

24. Guangfei G, Hailong Z, Guoxin F, Shisheng H, Xiaobing C, Xiaolong S, Xiaofei G, Xu Z (2014) Comparison of minimally invasive versus open transforaminal lumbar interbody fusion in two-level degenerative lumbar disease. Int Orthop 38(4):817-824

25. Mariscalco MW, Yamashita T, Steinmetz MP, Krishnaney AA, Lieberman IH, Mroz TE (2011) Radiation exposure to the surgeon during open lumbar microdiscectomy and minimally invasive microdiscectomy: a prospective, controlled trial. Spine (Phila Pa 1976) 36(3):255-260. doi:10.1097/BRS.0b013e3181ceb976 